ARTICLE

\title{
Best living concepts for elderly homeowners: combining a stated choice experiment with architectural design
}

\author{
loulia V. Ossokina ${ }^{1}$ (D) $\cdot$ Theo A. Arentze ${ }^{1} \cdot$ Dick van Gameren $^{2} \cdot$ Dirk van den Heuvel $^{2}$
}

Received: 9 October 2018 / Accepted: 2 November 2019 / Published online: 19 November 2019

(c) The Author(s) 2019

\begin{abstract}
In this paper we combine the insights from social sciences and architecture to design best living concepts for a specific target group, elderly homeowners. We perform a stated choice experiment to study residential preferences of this group and translate the results into an architectural design of senior-friendly housing. This methodological approach is novel to the literature. We derive the willingness-to-pay for different residential attributes and show how these attributes can be traded off against each other to create best living concepts. We discuss how these living concepts can be translated into customized architectural design while making use of standard architectural elements.
\end{abstract}

Keywords Residential preferences · Elderly households · Architectural design - Stated choice experiment

JEL Classification D12 $\cdot \mathrm{R} 21 \cdot \mathrm{R} 31$

Ioulia V. Ossokina

i.v.ossokina@tue.nl

Theo A. Arentze

t.a.arentze@tue.nl

Dick van Gameren

d.e.vangameren@tudelft.nl

Dirk van den Heuvel

d.vandenheuvel@tudelft.nl

1 Department of the Built Environment, Eindhoven University of Technology, De Zaale, 5612MB Eindhoven, The Netherlands

2 Department of Architecture, Delft University of Technology, Delft, The Netherlands 


\section{Introduction}

In various countries, the demand for senior dwellings is expected to rise. Yearly housing mobility rates of European elderly lie between 1 and 5\%, amounting to an annual flow of more than 1 million people changing house (Tatsiramos 2006; Gobillon and Wolff 2011; Abramsson and Andersson 2012). ${ }^{1}$ The absolute number is large and will be growing in the future because the proportion of $65+$ citizens in the population increases sharply, in Europe from $20 \%$ in 2015 to the expected $25 \%$ in 2040 (Eurostat 2017). ${ }^{2}$ Also, various governments currently make arrangements to stimulate the elderly to live independently at home for as long as possible (Mosca et al. 2017). Such policies may increase the motivation of people entering the third age to move to another home which will better suit their needs as they become older and in need of help.

Despite the relevance of the subject and the existence of research on housing priorities of the seniors, not much is known yet about how to translate these preferences into practical living concepts and architectural design. This paper develops and applies a novel methodology to design best living concepts for the elderly, based on the research in their residential preferences and architectural design principles. With 'best living concepts' we mean here practically and architecturally feasible combinations of dwelling, building and location attributes that are highly valued by the target group.

Our methodology combines insights from two disciplines: social sciences and architecture. First, we run a stated choice experiment to retrieve the willingness-to-pay of the elderly for a set of relevant-and mostly not yet studied-attributes of the dwelling, the building and the location. Then the attributes with the highest valuation are used as input for a flexible architectural design. The output of our research is also twofold. The stated choice experiment results in a consumer toolbox including a range of attributes of the dwelling, the building and the location. Each attribute is specified at multiple possible levels. For every attribute-level combination a monetary valuation of the willingness-to-pay is estimated. This allows to construct several best living concepts consisting of the most valuable combinations of the attributes. The architectural design results in an architectural toolbox that consists of construction elements that can be flexibly put together to realise the specified living concepts and their various combinations.

In selecting the dwelling, building and location attributes for the analysis, we account for the changes in the residential preferences that may take place near the third age. First, in anticipation of reduced mobility and increased health problems, people may find comfort, accessibility and safety of a dwelling and the surroundings more important than before (Gobillon and Wolff 2011; Feng et al. 2018; Costa-Font 2013; Liu et al. 2017; Pope and Kang 2010). ${ }^{3}$ Second, people may want to downsize because the need for living space decreases when children leave the house, or due to a fall in revenues after retirement (Bian 2016; Eichholtz and Lindenthal 2014; Painter and Lee 2009; Ong et al. 2015; Abramsson

\footnotetext{
1 Tatsiramos (2006) reports yearly housing mobility rates for elderly to lie between 1 and $5 \%$ in different European countries (the sample included Austria, Belgium, Denmark, Finland, France, Germany, Greece, Ireland, Italy, Netherlands, Portugal, Spain, United Kingdom). Gobillon and Wolff (2011) document substantial housing mobility at retirement for France: 31\% of the surveyed elderly aged between 68 and 92 claim to have moved around their retirement age. Abramsson and Andersson (2012) document a 25\% mobility rate of Swedish elderly within a 5 year period 2001-2006.

2 In China and in USA, one in four people will be older than 60 in 2030 (UN 2015).

3 Hillcoat and Ogg (2014) find that a bad 'fit' of the home to changing physical needs increases the propensity to move.
} 
and Andersson 2016). Finally, a new preference for shared facilities where elderly can meet each other, may arise (see Bohle et al. 2014 and the references therein). ${ }^{4}$ Reason is that retirement reduces a person's network, creates more time available for leisure, and thus increases the importance of social contacts in the direct neighbourhood. In constructing the choice situations for the choice experiment we assume that comfort and accessibility are necessary conditions to move. Thus, all the alternatives are specified as apartments in a building with a lift and equipped with senior-friendly facilities such as broad doors, no doorsteps, elevated toilets, etc. The attributes concerning safety, size and social cohesion vary between the alternatives and are subject of the analysis of this paper.

Our paper is related to different streams of literature. First, there is a small literature on designing dwellings that meet the needs of specific population groups. Cambell (2015) studies what design of social places is successful to support ageing in place. Wright et al. (2017) develop principles to house people with complex physical and cognitive disability. Nagib and Williams (2016) design physical elements of the home environment that can alleviate challenges faced by children with autism. These studies base architectural design on a qualitative research into housing needs. Our paper shows how quantitative research in housing preferences that uses a larger sample of individuals and a stated choice experiment, can contribute to architectural design.

Second, a growing literature studies the residential preferences of the elderly based on their residential moves. Much of this literature focusses on location choices. It shows that senior households move to places with highly valued consumer amenities including health care, high temperatures and low taxes (Chen and Rosenthal 2008; Önder and Schlunk 2015; Dorfman and Mandich 2016; Graves and Waldman 1991; Kim 2011), closer to their place of birth (Schaffar et al. 2018) or to their children (Bonnet et al. 2010). As for housing choice, elderly seem to choose for a smaller dwelling size (Bian 2016; Eichholtz and Lindenthal 2014; Painter and Lee 2009), shared living (Engelhardt and Greenhalgh-Stanley 2010) and rental housing (Herbers et al. 2014; Angelini and Laferrere 2012). Further, renters are more likely to move to institutionalized housing than home owners (Rouwendal and Thomese 2013). The revealed preferences approach used by these papers allows to examine the preferences for those residential attributes that are broadly adopted on the market and documented in the available databases. ${ }^{5}$ Our stated preferences approach makes it possible to study the valuation of attributes that are not yet widely adopted (like e.g. shared facilities), as well as characteristics of the building and the dwelling that are not well documented in databases (like e.g. the layout of the dwelling).

Third, our paper is related to stated preferences research-and specifically stated choice experiments - on residential preferences of the elderly. Using surveys and interviews among the elderly, various papers document willingness to move to smaller houses and rented dwellings (Abramsson and Andersson 2016), a strong desire to age in place (Costa-Font et al. 2009; Kramer and Pfaffenbach 2016), a pervasive desire for community and social connection (Bohle et al. 2014) and importance of the built environment quality

\footnotetext{
${ }^{4}$ Literature on assisted living shows that a necessity to share facilities can also have a negative impact on well-being and comfort, due to factors like gossiping (see e.g. Perkins et al. 2012). We do not focus on assisted living in this paper however. In the framework of independent living, we expect shared facilities to be valued positively.

5 Revealed preferences methods are also used to study housing preferences of other target groups, e.g. workers by skill level (Diamond 2016; Teulings et al. 2018), immigrants (Buchinsky et al. 2014), ethnic minorities (Bayer and McMillan 2012; Bayer et al. 2014).
} 
(Feng et al. 2018; Liu et al. 2017). In a stated choice experiment among Dutch seniors, De Jong et al. (2018) find existence of several groups with clearly different preferences. We are not aware of any other stated choice experiments with the elderly group, although there are quite a few such experiments with other target groups (see Verhetsel et al. 2017, for housing preferences of students; Del Mistro and Hensher 2009, for slum inhabitants in developing countries; Ibraimovic and Masiero 2014, Ibraimovic and Hess 2017, for ethnic minorities; Tillema et al. 2010, for car commuters, etc.). Our paper adds to this literature by studying the preferences of the elderly for dwelling, building, location attributes that are specifically connected to safety, social cohesion and shared facilities, and by doing this in an experimental setting. We show furthermore how to translate insights about residential preferences to architectural design.

Finally, several studies show that the well-being of the elderly is closely related to their living comfort. Morris (2017) and Colleman et al. (2016) find for the elderly in respectively Australia and New Zeeland that uncertainty about the quality of the dwelling leads to stress and anxiety and reduces well-being. Herbers and Mulder (2017) document that the relationship between housing and well-being exists in various countries. ${ }^{6}$ Our paper offers new insights into how a dwelling design can be used to increase the living comfort and thus the well-being of the elderly.

There are two reasons why our results may be especially interesting for practitioners working in the area of elderly housing development. First, we offer developers new insights into the senior residents' priorities and the way these can be translated into the living concepts. Hu et al. (2014) suggests that developers do not always have a complete overview of these priorities, and anecdotal evidence provides support to this conclusion. ${ }^{7}$ The consumer toolbox we develop, shows how different residential attributes can be traded off against each other to create best living concepts that meet certain conditions. Second, our study contributes to solving the trade-off between standardization and customization that developers might face when constructing elderly dwellings (see Hofman et al. 2006). The consumer toolbox and the architectural toolbox allow to design various customized living concepts while making use of standard elements. This can be especially interesting in the situation when large numbers of elderly dwellings need to be constructed within a limited time span.

The rest of the paper is organized as follows. Sections 2, 3 and 4 discuss our study into the residential preferences of the elderly: Sect. 2 deals with the model and the data, Sect. 3 introduces the stated choice experiment, Sect. 4 reports the results and discusses the consumer toolbox. Section 5 discusses the development of the architectural toolbox based on the results of the previous sections. Section 6 presents a discussion and Sect. 7 concludes.

\section{Study into the residential preferences: model and data}

To empirically estimate residential preferences of senior households we use as a baseline the traditional multinomial logit model developed by McFadden (1978). In this model, utility person $i$ obtains from dwelling $h$ is defined as:

\footnotetext{
6 See also Feng et al. (2018) and Liu et al. (2017) for China.

7 For instance, a new town Blauwestad designed in early 2000s in the North of the Netherlands, had richer elderly as an important target group, but failed by far to attract the expected number of residents (Noordelijke Rekenkamer 2010).
} 
Table 1 Description of the respondents

\begin{tabular}{|c|c|c|c|}
\hline \multicolumn{2}{|c|}{ Socio-economic characteristics of the respondent } & \multicolumn{2}{|l|}{ Current dwelling and moving preferences } \\
\hline Aged 65-69 & $63 \%$ & Lives in an apartment & $15 \%$ \\
\hline Aged 70-74 & $37 \%$ & Lives in a one-family dwelling & $85 \%$ \\
\hline Couple & $86 \%$ & Size dwelling, median & $120 \mathrm{~m}^{2}$ \\
\hline Alone & $14 \%$ & & \\
\hline Low educated & $22 \%$ & Size of garden, for one-family dwellings, & $100 \mathrm{~m}^{2}$ \\
\hline Middle educated & $38 \%$ & median & \\
\hline High educated & $40 \%$ & & \\
\hline $\begin{array}{l}\text { Household yearly gross income less than } \\
€ 30,000\end{array}$ & $3 \%$ & $\begin{array}{l}\text { Value of the dwelling, as specified by the } \\
\text { fiscal authorities, median }\end{array}$ & $€ 225,000$ \\
\hline $\begin{array}{l}\text { Household yearly gross income } € 30,000 \text { - } \\
€ 50,000\end{array}$ & $71 \%$ & & \\
\hline $\begin{array}{l}\text { Household yearly gross income more than } \\
€ 50,000\end{array}$ & $26 \%$ & & \\
\hline Retired & $87 \%$ & & \\
\hline
\end{tabular}

$$
U_{i h}=\alpha+\beta X_{h}+\varepsilon_{i h},
$$

where $X_{h}$ is a vector of the attributes of the dwelling, building and location, $\beta$ is a vector of coefficients, $\alpha$ is a constant and $\varepsilon_{i h}$ is a Gumbel-distributed error term.

The probability that person $i$ chooses dwelling $h$ out of the choice set $H$ of alternative dwellings, can be derived as:

$$
\operatorname{Pr}[h]=\frac{\exp \left(\beta X_{h}\right)}{\sum_{m \in H} \exp \left(\beta X_{m}\right)} .
$$

Coefficients $\beta_{j} \in \beta$ describe the relative importance individuals attach to the $j$-th element of the vector $X_{h}$. Let $\beta_{0}$ be the coefficient by a monetary attribute of the dwelling, e.g. the rent or the price. Then the willingness to pay for attribute $j$, expressed in monetary terms, can be written as:

$$
W T P_{j}=\beta_{j} / \beta_{0} .
$$

We estimate the parameters of (2) using data from a stated choice experiment performed among elderly Dutch homeowners. We focus on homeowners for several reasons. First, they are an important group in the housing market: some 50\% of elderly Dutch households are homeowner. Second, in the Netherlands, homeowners are more likely than renters to have means to realize their residential preferences. Statistics Netherlands (2018) reports e.g. that the gross disposable income of renters is on average twice as low as that home owners. Third, using information on housing prices we can calculate the willingness-to-pay for various residential attributes.

The experiment was administered in an on-line survey and offered to the participants of a large national Dutch on-line panel in the age group 65-74. In the Netherlands, in 2017, the age of 65 was the average retirement age, so our respondents are on average people who have recently retired. Given the target group of our study, we selected participants who are homeowner and whose current dwelling has a value between 100,000 and 500,000 euro. 
The respondents were first asked for information on their socio-economic characteristics and their current dwelling; afterwards they were offered the stated choice experiment.

The responses were collected on working days during the period 6 June to 7 July 2017. Our initial sample consisted of 460 respondents. We have removed the questionnaires with missing information about the socio-economic characteristics of the individual, as well as questionnaires that were completed in less than $10 \mathrm{~min}$. The 10-min threshold was chosen to filter out respondents who did not take sufficient time to read the questions thoroughly. After these corrections, 423 respondents were left. Table 1 reports the descriptive characteristics of the respondents and their current dwellings. The majority of our respondents are people aged between 65 and 70 living together with a partner in a single-family dwelling. High educated are somewhat overrepresented, as well as persons with higher than median income. The sample is representative for different regions and living environments of the Netherlands. Each of the 12 provinces of the country is represented, with at least 15 respondents. Some $50 \%$ respondents live in large or middle large cities, around $13 \%$ live in rural areas, and the rest lives in small towns.

To obtain more information about the extent to which our respondents are concerned about their living comfort and current living conditions, we have asked a number of questions about the moving preferences. We also asked respondents whether they think the dwelling will stay suitable for their needs when they get older. Table 2 reports the results. Some $60 \%$ of the respondents think that they will not be able to live in their current dwelling with sufficient comfort when they get older. Most of these people expect though that the necessary comfort can be achieved through adjustments. Furthermore, some $20 \%$ of the respondents considers moving.

\section{Set-up of the stated choice experiment}

In the stated choice experiment, respondents were offered twelve randomly composed choice sets, consisting of two alternative dwellings each. The alternative dwellings were specified as apartments sized between 70 and $110 \mathrm{~m}^{2},{ }^{8}$ situated in a building with a lift and specifically designed for elderly needs (broader doorways, elevated toilet, etc.) The price levels were pivoted around the self-reported market value of the current dwelling of the respondent. The experiment required first that for each choice set, the respondents indicated the living satisfaction they expected to obtain in each of the two alternatives, as compared to their current dwelling (choice 1). They could select out of 5 values: much lower than now, lower than now, equal to now, higher than now, much higher than now. Afterwards, the respondents were asked to make a choice between the two offered alternatives assuming the current dwelling was no longer available as a valid option (choice 2). We dropped inconsistent observations, in which choice 1 and choice 2 contradicted each other. Figure 1 presents a print screen of a choice situation.

To specify the dependent variable for the estimation of the model, we exploit information about choice 1 . The dependent variable is assigned value 1 for the alternative which yields the highest living satisfaction to the respondent (this can be: alternative 1 , alternative 2 or current dwelling), and zero for the other alternatives.

\footnotetext{
${ }^{8}$ We chose to consider apartments because these are easier adjustable to physical needs of seniors. Although this paper focusses on a specific segment of the housing market, our method can be applied to other product-market combinations as well.
} 


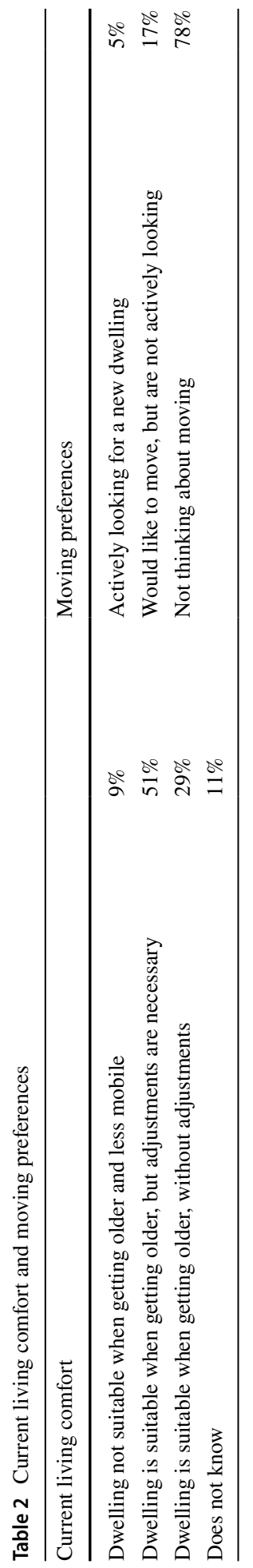




\section{U C Endhoven Universiteit Happy Senior Living}

\begin{tabular}{|c|c|c|c|}
\hline \multicolumn{4}{|l|}{ This part of the survey concerns your future dwelling } \\
\hline Dwelling charasteristics & Dwe & & Dwelling 2 \\
\hline Living space & $70 \mathrm{~m}$ & & $110 \mathrm{~m} 2$ \\
\hline Garden or balcony & Garc & & Balcony $12 \mathrm{~m} 2$ \\
\hline Common garden, adjacent to the building & No & & $\begin{array}{l}\text { Yes, private garden, only accessible } \\
\text { for the residents }\end{array}$ \\
\hline Openness of the dwelling composition & $\begin{array}{l}\text { Clos } \\
\text { livin }\end{array}$ & & $\begin{array}{l}\text { Open kitchen, doorway between } \\
\text { living and sleeping rooms }\end{array}$ \\
\hline Location with respect to a larger city & With & & $\begin{array}{l}\text { In a suburb, } 15 \text { minutes driving } \\
\text { distance from a larger city }\end{array}$ \\
\hline Price, in comparison with the current dwelling & $10 \%$ & & Same as the current dwelling \\
\hline $\begin{array}{l}\text { What living statisfaction do you expect from this } \\
\text { choice, compared with now? }\end{array}$ & same & $\checkmark$ & higher than now \\
\hline Choice 2 & & & - \\
\hline
\end{tabular}

Fig. 1 Print screen of a choice set

The twelve choice sets the respondents were offered, were divided in three separate groups of four choice sets each. In the first group the alternatives were specified in terms of the dwelling attributes, keeping the building and the location characteristics fixed. In the second group the alternatives were specified in terms of building attributes, and in the third group the alternatives were specified in terms of location attributes. In this way, the choice experiment was split up in three separate sub experiments to reveal the preferences for dwelling, building and location attributes, respectively. This partitioning allowed us to estimate the preferences for a large set of dwelling attributes without introducing too much complexity into the stated choice questions. In all three sub experiments two attributes were common: price (in order to be able to calculate the willingness-to-pay) and location with respect to a large city.

In this paper we focus on the sub experiments concerning the dwelling and the building. The definitions of the attributes in these sub experiments are reported in Table 3. Each attribute was specified at three levels, denoted as 0,1 and 2. The attributes and the levels of each attribute were chosen carefully taking into consideration the relevance for key architectural design choices as well as the expected impact on the preferences of residents. For example, parking and availability of communal spaces have significant implications both for the building design and the residents' preferences. To compose the experiments we used an orthogonal and balanced fractional factorial design (see Hensher et al. 2015).

In the estimation, we pool the sub experiments imposing a restriction that the coefficients by the common attributes are the same. ${ }^{9}$ Data collected from the sub experiments should be seen as separate data sources which might differ by the scale of the coefficients (Hensher et al. 2015). To account for this, we will estimate a scale factor for each sub experiment.

\footnotetext{
${ }^{9}$ Effect coding was used to incorporate the attributes in the model. Without the loss of generality the attributes that are missing in a sub experiment (dwelling for the building part and building for the dwelling part) were assigned level 0.
} 


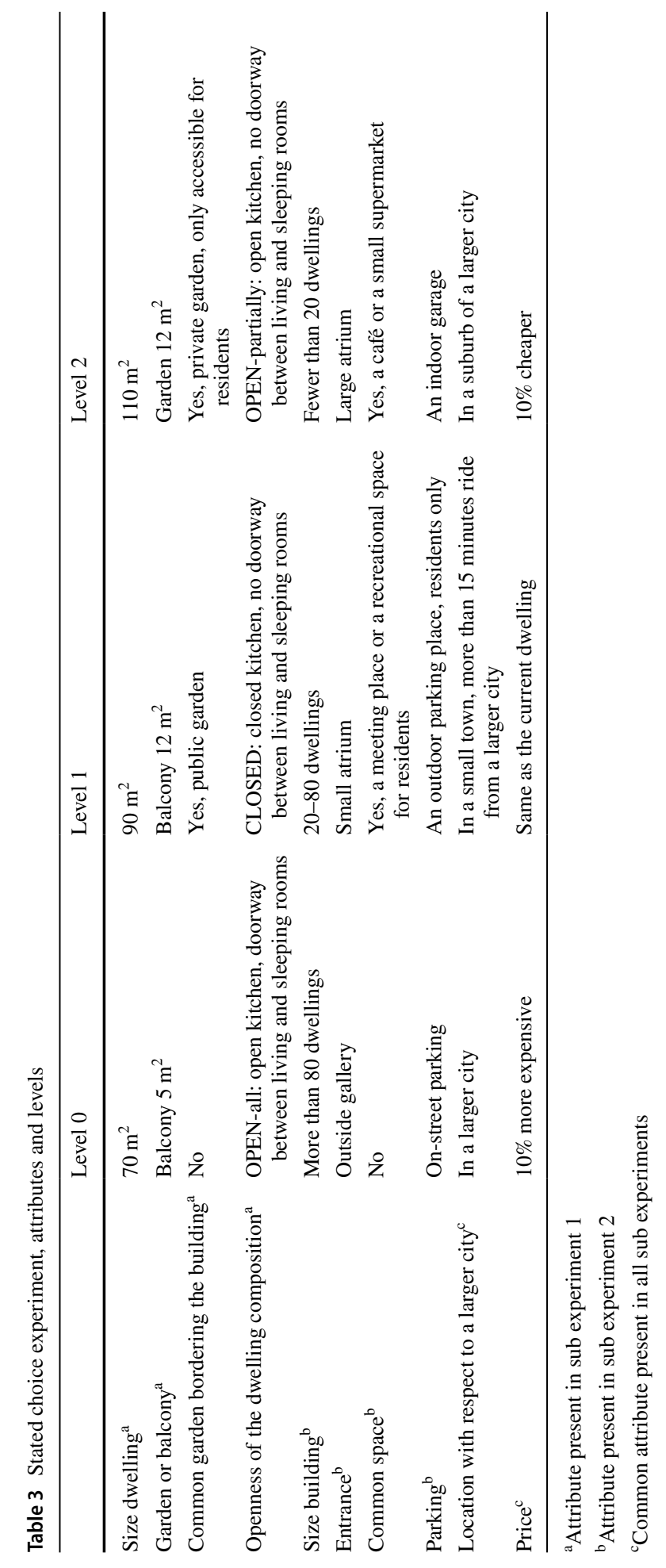




\section{Results of the choice experiment}

\subsection{Estimation results}

The alternative dwellings offered in the choice experiment to the respondents differ in various respects from their current dwellings. Choosing for one of these alternatives implies in many cases downsizing in space, both within the house (living) and outside the house (garden). In our experiment, this downsizing may be compensated by senior-friendly facilities in the dwelling, a more comfortable and safe living environment and additional shared space (a common garden, a meeting place for the residents and other amenities within the building). Around half of the respondents (217 out of 423) expect a higher living satisfaction from at least one of the alternatives offered in the choice experiment, when compared to their current dwelling.

Table 4 reports the estimation results for two specifications: a baseline model in which all scale factors are constrained to one, and a model in which only one (reference) scale factor is constrained to one. In the latter specification, the sub experiment based on dwelling attributes is chosen as reference, and the scale factor for the sub experiment based on building attributes is estimated to be 1.077. An LR-test comparing the two specifications, allows to reject the hypothesis that the model with unconstrained scale factors offers a better goodness-of-fit than the baseline model. Henceforth we take the baseline model as our preferred specification.

The baseline model yields a reasonable fit of 17\%. The coefficients in Table 4 are reported taking level 1 of each attribute as a reference and should be interpreted as a decrease/increase in utility from changing the level of an attribute from the reference to level 0 respectively 2 . The coefficients are mostly highly significant and have the expected signs. In other words, increasing the level of an attribute generally leads to an increase in utility and vice versa. We discuss the interpretation of the coefficients in the next section.

\subsection{Consumer toolbox and the best living concepts}

In Fig. 2 below the results of the stated choice experiment are translated into an easy to interpret consumer toolbox. The toolbox contains all studied attributes and their levels. For each of these, the willingness-to-pay (WTP) is calculated, in comparison to a reference dwelling. ${ }^{10}$ Attribute levels that increase utility (have a positive willingnessto-pay) compared to the reference dwelling, have a white color in the toolbox, attribute levels that decrease utility have a dark grey color. The middle row (light grey) of the toolbox contains the attribute levels of the reference dwelling; these are also summarized below:

\footnotetext{
${ }^{10}$ To calculate the willingness-to-pay, we applied Eq. (3) with in the denominator the coefficient $\beta_{0}=-0.214$ that reflects the change in the utility connected to a $10 \%$ increase in the price of a dwelling.
} 
Table 4 Estimation results

\begin{tabular}{|c|c|c|c|c|c|}
\hline \multirow[t]{2}{*}{ Attribute } & \multirow[t]{2}{*}{ Level } & \multicolumn{2}{|l|}{ Baseline } & \multicolumn{2}{|c|}{ With scale effects } \\
\hline & & Value & t-val. & Value & t-val. \\
\hline \multicolumn{6}{|l|}{ Constant } \\
\hline$\alpha$ & & $-0.740 * * *$ & -7.23 & $-0.740 * * *$ & -7.23 \\
\hline \multicolumn{6}{|c|}{ Size dwelling } \\
\hline$\beta 0$ & $70 \mathrm{~m}^{2}$ & $-0.655^{* * *}$ & -5.18 & $-0.650 * * *$ & -4.90 \\
\hline$\beta 1$ & $90 \mathrm{~m}^{2}$ & 0 & & 0 & \\
\hline$\beta 2$ & $110 \mathrm{~m}^{2}$ & $0.511 * * *$ & 4.81 & $0.516^{* * *}$ & 4.52 \\
\hline \multicolumn{6}{|c|}{ Balcony/garden } \\
\hline$\beta 0$ & Balc. $5 \mathrm{~m}^{2}$ & $-0.368 * * *$ & -3.03 & $-0.364 * * *$ & -2.86 \\
\hline$\beta 1$ & Balc. $12 \mathrm{~m}^{2}$ & 0 & & 0 & \\
\hline$\beta 2$ & Gard. $12 \mathrm{~m}^{2}$ & $0.352 * * *$ & 3.21 & $0.356^{* * *}$ & 3.06 \\
\hline \multicolumn{6}{|c|}{ Openess dwelling } \\
\hline$\beta 0$ & Open-all & $-0.331 * * *$ & -2.77 & $-0.328 * * *$ & -2.63 \\
\hline$\beta 1$ & Closed & 0 & & 0 & \\
\hline$\beta 2$ & Open-partially & -0.118 & -1.01 & -0.116 & -0.97 \\
\hline \multicolumn{6}{|c|}{ Size building } \\
\hline$\beta 0$ & $>80$ dwellings & $-0.279 * *$ & -2.33 & $-0.321 * *$ & -1.86 \\
\hline$\beta 1$ & 20-80 dwellings & 0 & & 0 & \\
\hline$\beta 2$ & $<20$ dwellings & $0.479 * * *$ & 4.51 & $0.498 * * *$ & 3.51 \\
\hline \multicolumn{6}{|l|}{ Parking } \\
\hline$\beta 0$ & No & $-0.672 * * *$ & -5.41 & $-0.744 * * *$ & -2.99 \\
\hline$\beta 1$ & Outdoor & 0 & & 0 & \\
\hline$\beta 2$ & Indoor & $0.306 * * *$ & 2.94 & $0.312 * * *$ & 2.60 \\
\hline \multicolumn{6}{|l|}{ Entrance } \\
\hline$\beta 0$ & Outdoor & $-0.335^{* * *}$ & -2.8 & $-0.378 * * *$ & -2.14 \\
\hline$\beta 1$ & Indoor, small atrium & 0 & & 0 & \\
\hline$\beta 2$ & Indoor, large atrium & 0.0930 & 0.85 & 0.080 & 0.67 \\
\hline \multicolumn{6}{|c|}{ Common garden } \\
\hline$\beta 0$ & No garden & -0.143 & -1.20 & -0.140 & -1.13 \\
\hline$\beta 1$ & Public garden & 0 & & 0 & \\
\hline$\beta 2$ & Private garden & 0.068 & 0.6 & 0.071 & 0.6 \\
\hline \multicolumn{6}{|c|}{ Common space } \\
\hline$\beta 0$ & No & $-0.387 * * *$ & -3.28 & $-0.432 * * *$ & -2.39 \\
\hline$\beta 1$ & Meeting & 0 & & 0 & \\
\hline$\beta 2$ & Café or superm. & -0.012 & -0.11 & -0.026 & -0.20 \\
\hline \multicolumn{6}{|l|}{ Location } \\
\hline$\beta 0$ & City & $-0.174 * *$ & -2.50 & $-0.175^{* *}$ & -2.44 \\
\hline$\beta 1$ & Town & 0 & & 0 & \\
\hline$\beta 2$ & Suburb & 0.036 & 0.52 & 0.038 & 0.55 \\
\hline \multicolumn{6}{|l|}{ Price } \\
\hline$\beta 0$ & $+10 \%$ & $-0.214 * * *$ & -3.03 & $-0.217 * * *$ & -2.88 \\
\hline$\beta 1$ & Equal & 0 & & 0 & \\
\hline$\beta 2$ & $-10 \%$ & 0.030 & 0.44 & 0.030 & 0.43 \\
\hline
\end{tabular}


Table 4 (continued)

\begin{tabular}{|c|c|c|c|c|c|}
\hline \multirow{2}{*}{ Attribute } & \multirow[t]{2}{*}{ Level } & \multicolumn{2}{|c|}{ Baseline } & \multicolumn{2}{|c|}{ With scale effects } \\
\hline & & Value & t-val. & Value & t-val. \\
\hline \multicolumn{6}{|c|}{ Scale effects } \\
\hline$\tau 1$ & & & & 1 & Fixed \\
\hline$\tau 2$ & & & & 1.077 & 4.30 \\
\hline \multicolumn{3}{|c|}{ LR test ( $\chi^{2}, p$ value in parentheses) } & & \multicolumn{2}{|c|}{$0.25(0.88)$} \\
\hline Rho-squa & & \multicolumn{4}{|l|}{0.171} \\
\hline Rho-squa & & \multicolumn{4}{|l|}{0.165} \\
\hline
\end{tabular}

$* * *$ Significant at $1 \%$; **significant at $5 \%$; *significant at $10 \%$

- an apartment, elderly-accessible and equipped with amenities as: a lift in the building, an elevated toilet, broad doorways, etc.

- living space $90 \mathrm{~m}^{2}$,

- balcony $12 \mathrm{~m}^{2}$,

- closed kitchen and no doorway between the living and the sleeping rooms;

- medium large building of between 20 and 80 dwellings,

- public garden next to the building,

- common meeting space for the residents of the building,

- entrance through an indoor small atrium,

- outdoor parking space, residents only;

- located in a smaller town on a distance of more than 15 minutes drive from a larger city;

- a price level of 225,000 euro.

\begin{tabular}{|c|c|c|c|c|c|c|c|c|c|}
\hline & \begin{tabular}{|c|} 
Size \\
dwelling
\end{tabular} & $\begin{array}{l}\text { Balcony } \\
\text { /garden }\end{array}$ & $\begin{array}{l}\text { Openness } \\
\text { dwelling }\end{array}$ & $\begin{array}{c}\text { Size } \\
\text { building }\end{array}$ & Parking & Entrance & \begin{tabular}{|c|}
$\begin{array}{c}\text { Common } \\
\text { garden }\end{array}$ \\
\end{tabular} & $\begin{array}{c}\text { Common } \\
\text { space }\end{array}$ & Location \\
\hline $\begin{array}{l}\text { higher } \\
\text { value/ } \\
\text { utility }\end{array}$ & $\begin{array}{c}110 \mathrm{~m} 2 \\
(+25 \% \\
\text { value })\end{array}$ & \begin{tabular}{|c|} 
Ground \\
floor, \\
garden \\
$12 \mathrm{~m} 2$ \\
$(+15 \%$ value $)$ \\
\end{tabular} & $\begin{array}{c}\text { Open kitchen, } \\
\text { no doorway } \\
\text { living-sleeping }\end{array}$ & $\begin{array}{c}<20 \\
\text { dwellings } \\
(+20 \% \\
\text { value })\end{array}$ & $\begin{array}{c}\text { Indoor } \\
\text { parking } \\
\text { garage } \\
\text { (+15\% value) }\end{array}$ & $\begin{array}{c}\text { Large } \\
\text { hall/atrium } \\
\text { with lift }\end{array}$ & $\begin{array}{c}\text { Yes, } \\
\text { private, } \\
\text { residents } \\
\text { only }\end{array}$ & $\begin{array}{c}\text { Yes, a small } \\
\text { cafetaria or a } \\
\text { supermarket }\end{array}$ & $\begin{array}{c}\text { Suburbs of a } \\
\text { larger city }\end{array}$ \\
\hline $\begin{array}{l}\text { reference } \\
\text { dwelling }\end{array}$ & $90 \mathrm{~m} 2$ & $\begin{array}{c}\text { No ground } \\
\text { floor, } \\
\text { balkony } \\
12 \mathrm{~m} 2\end{array}$ & $\begin{array}{c}\text { Closed } \\
\text { kitchen, no } \\
\text { doorway } \\
\text { living-sleeping }\end{array}$ & $\begin{array}{c}20-80 \\
\text { dwellings }\end{array}$ & $\begin{array}{l}\text { Outdoor } \\
\text { parking } \\
\text { reserved for } \\
\text { residents }\end{array}$ & $\begin{array}{l}\text { Small hall } \\
\text { with a lift }\end{array}$ & $\begin{array}{l}\text { Yes, } \\
\text { public } \\
\text { garden }\end{array}$ & $\begin{array}{c}\text { Yes, a } \\
\text { recreation } \\
\text { area/ a } \\
\text { meeting place }\end{array}$ & $\begin{array}{c}\text { Small town } \\
\text { more than } 15 \\
\text { min driving to } \\
\text { larger city }\end{array}$ \\
\hline $\begin{array}{l}\text { lower } \\
\text { value/ } \\
\text { utility }\end{array}$ & $\begin{array}{l}70 \mathrm{~m} 2 \\
(-30 \% \\
\text { value })\end{array}$ & $\left|\begin{array}{c}\text { No ground } \\
\text { floor, } \\
\text { balkony } 5 \mathrm{m2} \\
\text { (-15\% value) }\end{array}\right|$ & $\begin{array}{c}\text { Open kitchen, } \\
\text { doorway } \\
\text { living-sleeping } \\
\text { (-15\% value) }\end{array}$ & $\begin{array}{c}>80 \\
\text { dwellings } \\
(-15 \% \\
\text { value })\end{array}$ & $\begin{array}{l}\text { On-street } \\
\text { public } \\
\text { parking } \\
\text { (-30\% value) }\end{array}$ & $\begin{array}{c}\text { Outdoor } \\
\text { gallery } \\
\text { (-15\% } \\
\text { value) }\end{array}$ & $\begin{array}{c}\text { NO } \\
(-5 \% \\
\text { value })\end{array}$ & $\begin{array}{c}\text { NO } \\
\text { (-20\% value) }\end{array}$ & $\begin{array}{l}\text { Larger city } \\
\text { (-10\% value) }\end{array}$ \\
\hline
\end{tabular}

Fig. 2 Consumer toolbox: best living concepts (WTP is rounded up to the nearest 5\%) 
The consumer toolbox offers clear trade-offs between improving and worsening the levels of certain attributes. Thus it allows to construct a variety of best living concepts that meet various financial, geographical and other restrictions. Consider, for instance, a situation in which an entrance through an outdoor gallery is desirable, due to technical or cost considerations. This reduces the value of a dwelling for the elderly by $15 \%$. Our toolbox allows to find out which other attributes can be improved to compensate for this loss. For example, a smaller building size or a larger size of the dwelling could do the job.

Let us consider now the trade-offs between specific attribute levels in more detail. An increase in the size of the dwelling from 90 to $110 \mathrm{~m}^{2}$ leads to $25 \%$ higher value (willingness-to-pay) for the elderly. A similar decrease in the size (from 90 to $70 \mathrm{~m}^{2}$ ) results in a $30 \%$ lower WTP. For a reference dwelling with a value of 225,000 euro that implies an average squared meter price of some three thousand euro $/ \mathrm{m}^{2}$, which is close to the average $\mathrm{m}^{2}$ apartment price in the Netherlands in $2017 .^{11}$

Having a private outside space of a reasonable size is valuable. A balcony of $12 \mathrm{~m}^{2}$ increases the willingness-to-pay with $15 \%$ as compared to a balcony of $5 \mathrm{~m}^{2}$. This valuation suggests that when designing senior dwellings, a larger balcony than $12 \mathrm{~m}^{2}$ needs to be considered as well. Availability of a garden of $12 \mathrm{~m}^{2}$ instead of a balcony has a positive effect of $15 \%$.

The calculated valuations of the building characteristics suggest that safety, social cohesion and comfort play an important role for the elderly. For instance, the necessity to park onstreet may imply a higher chance of car robbery and a necessity to cruise for parking. It leads to a drop in the willingness-to-pay with $30 \%$. An indoor garage, on the other hand, increases the value elderly attach to the dwelling with some $15 \%$. An apartment building with more than 80 dwellings may imply a lower social cohesion, a higher chance that if something happens to a person, this will go unnoticed. This has a negative effect equal to $15 \%$. A very small building with fewer than 20 apartments increases the WTP with 20\%. An entrance via an outdoor gallery (lower transparency, less safety) has a negative impact of some $15 \%$. Another important aspect is a possibility of social contacts with neighbours. Availability of a common space in the building increases the WTP with $20 \%$ of the dwelling price.

The location preferences suggest that the elderly make a trade-off between accessibility of amenities and facilities present in a large city, and the social cohesion of a smaller place. Living in a larger city is least attractive, yielding a $10 \%$ lower value than a suburb or a small town.

\section{Architectural design}

In order to link measured preferences to design solutions, we transform the consumer toolbox into an architectural toolbox. We emphasize that there is no one-to-one correspondence between the preferences and the architectural solutions. Rather there are multiple ways in which the attributes can be implemented in the design. The architectural toolbox had to meet the requirement of flexibility, i.e. contain architectural elements that allow to compose different combinations from the consumer toolbox. Furthermore, we paid attention to enabling a social and communal way of living without compromising on privacy, and to ensuring accessibility and comfort for the elderly. Finally, solutions were developed for an urban and a semi-urban setting.

11 The Dutch Association of Real Estate Brokers (NVM 2018) reports an average price of 2500 euro/ $/ \mathrm{m}^{2}$ in 2017. 


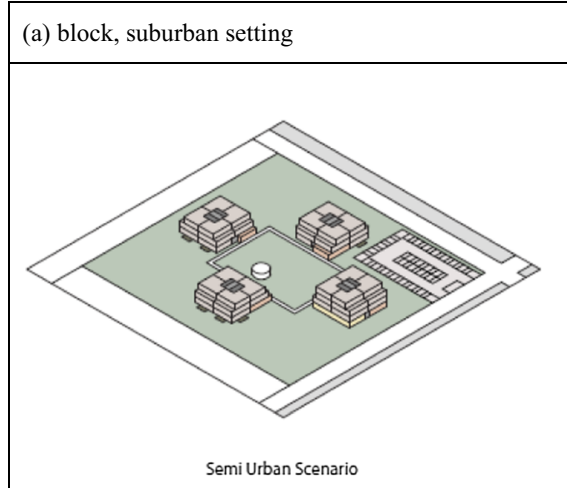

(c) ground floor parking

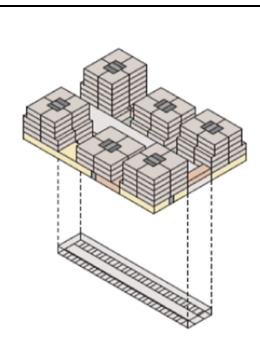

Ground Floor Parking

(e) main element, building

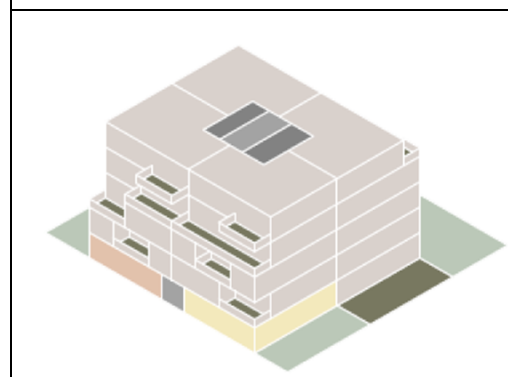

(g) ground floor building

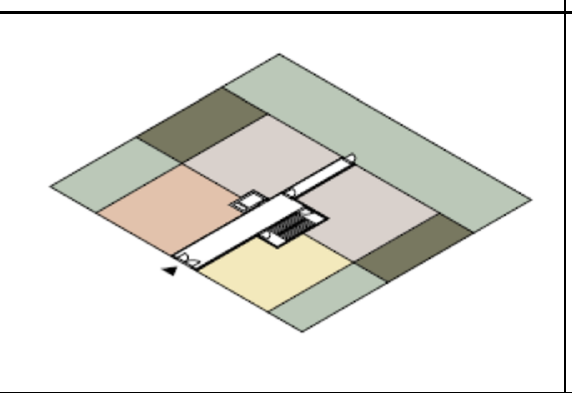

(h) communal spaces (lift, garden, shop, meeting place)

Fig. 3 Architectural toolbox 
Figure 3 contains the elements of the architectural toolbox. The main element is the building, described in panels (e)-(h). A combination of several buildings forms a block (panels a-d). For presentation purposes, we start with the discussion of the block and then deal with the building.

Panels (a) and (b) illustrate two possible block compositions, left in a low density environment (semi-urban setting) and right in a high density environment (urban setting). Grouping several apartment buildings together in a block allows to share a common garden and a number of communal spaces and services. While communal spaces are mostly located on the ground floor, in the semi-urban setting it is also possible to create a separate building in the common garden, to increase the sense of community. The communal spaces in different buildings are connected to each other with a walking passage; they all can be reached from inside each building without walking outside.

In both settings, urban and semi-urban, measures are taken to protect privacy. First, every apartment building within the block has its own entrance directly from the street, its own lift and vertical circulation. In the semi-urban setting, the shared garden is located both, in the middle of the block and on the outside border, to increase the distance to the street. In the urban setting, enabling privacy presents a larger challenge and can be achieved by a number of measures: increase the distance between the building and the street by introducing a walking strip; locate the ground floor apartments $50 \mathrm{~cm}$ higher than the street level; locate communal spaces on the side facing the street, and apartments overlooking the garden.

Panels (a), (c) and (d) illustrate three possible locations for parking. In panels (a) and (c), parking is realized on the ground level, respectively in a corner of the block and in the middle of the block. In the former solution, the parking place offers a direct entrance to the passage connecting different buildings, so that walking from the apartment to the parking is indoors. The latter solution makes more space available for other construction, but sacrifices the communal garden in the middle of the block. Panel (d) shows the most expensive solution: an underground parking.

Panel (e) zooms in at the building, which consists of four dwellings per floor, central core circulation with lift and stairs. The entrance leads to a large atrium (panel (f)) from where the stairs and the lift can be reached. The building allows different combinations of the attribute levels from the consumer toolbox. The size of the four dwellings can be easily adjusted between 90,110 and $70 \mathrm{~m}^{2}$. The number of floors can vary to adapt to different needs and urban settings. For instance, a five-floor building houses 20 dwellings and a tenfloor building houses 40 dwellings. Dwellings on higher floors are equipped with balconies; dwellings on the ground floor with a small garden.

Panels (g) and (h) zoom in at communal spaces within the building. Communal functions include an atrium, a lift, and other spaces such as residents-only meeting rooms and a restaurant, a small supermarket or a shop.

\section{Discussion}

Our methodology has allowed us to both, obtain insights into the housing priorities of the elderly and translate these insights into practically and architecturally feasible living concepts. Concurrently, the methodology entails a number of limitations and simplifications.

First, the stated choice approach we used to study preferences, has a number of known caveats. When respondents do not actually plan to move and to pay for a new house (in our 
case $80 \%$ does not plan to move), their real housing priorities and attribute valuation may be difficult to measure correctly. Respondents might give poorly thought out answers if the situation is hypothetical (hypothetical bias) or overstate their true valuation (strategic bias). Although a comparison of the insights from revealed and stated preferences studies (Sect. 1) suggests that actually measured moving behaviour does not contradict results from measurements based on stated preferences, it is important to keep these limitations in mind.

Second, for the purpose of transparency and tractability of our results, we have put restrictions on both, the target group as well as the type of dwelling alternatives studied. By focussing on home owners only, another large group of the elderly-renters and especially social renters-was left out of consideration. It might be even more important to get insight into their housing needs and develop practical tools to translate these needs to design. Reason is that renters are on average less well-off than owners and thus face larger financial restrictions in housing choices (see Statistics Netherlands 2018). This may make the possibilities to realise their housing needs more limited and the development of best living concepts more challenging. We leave this for future research. Further, we focussed on young elderly (65-75 years old) and specified dwelling alternatives as apartments. Thus we left for further research the question about the valuation of single family dwellings and their attributes by seniors, as well as the question about housing preferences of older seniors.

Finally, the limited size of our dataset prevented from performing some types of more detailed analysis on the housing priorities of the seniors. Examples involve e.g. a research question about the impact of the individual's personality and socio-economics on the preferences. De Jong et al. (2018) provides some insights on this subject and suggests that there exist divergent types of housing preferences among the seniors. Another relevant research question that could be studied when more data are available, concerns existence of regional differences in the housing priorities of the elderly. Finally, an important issue concerns the way people make trade-offs between dwelling attributes. In this study we assumed that all different attributes and elements of a dwelling, building and location are seen by respondents as independent and can be traded off against each other. Relaxing this prior and studying the reference-dependence of residential preferences of the seniors is a promising direction for further analysis.

\section{Conclusion}

This paper developed and applied a novel approach to designing best living concepts for a specific target group—elderly—while combining research into their housing preferences with architectural design. Using a stated choice experiment we first obtained valuations of the elderly for different attributes of a dwelling, building and location. Then a consumer toolbox has been developed-a tool that facilitates construction of best living concepts as combinations of residential attributes with the highest valuation. Finally, a flexible architectural toolbox was constructed that allows to translate various combinations from the consumer toolbox to architectural design.

Our results suggest that residential attributes connected to safety (e.g. indoor parking or a smaller building) and social cohesion (e.g. a communal meeting space) play an important role for the elderly. The consumer toolbox shows how different residential attributes can be traded off against each other to create best living concepts that meet certain conditions. Imagine that a valuable for the elderly facility like an indoor garage is not feasible due to 
cost considerations. The consumer toolbox allows to calculate what other attributes (e.g. a smaller size of the building or shared facilities) can be added to the living concept to keep it attractive for the target group. The architectural toolbox translates attributes from the consumer toolbox into flexible architectural elements. For illustration, these have been put together into two possible dwelling-building-block designs, a low density (semi-urban) setting and a high density (urban) setting.

Our study shows that combining a research into the residential preferences with the architectural design leads to important synergy effects. The consumer toolbox and the architectural toolbox we have developed, can be used to realise different concepts of senior housing that fit various practical restrictions and requirements. Financial limitations as well as specific characteristics of a location may make it impossible to realise the first-best living concept. The consumer toolbox yields insights into what attributes can be sacrificed with the smallest loss in the value of a dwelling for the seniors. The architectural toolbox offers construction elements that allow to adjust the design to a specific situation.

The demand for elderly housing is likely to be growing in the coming decades. Our study contributes to better understanding the living needs of the seniors and to producing tools that translate these needs into practically feasible architectural solutions.

Acknowledgements We thank David Hensher for his comments and suggestions. We thank Arjen Deetman and Giorgio Larcher for excellent research assistance. The authors gratefully acknowledge financial support from the 4TU Lighthouse grant.

Funding This study was funded with the 4TU.Bouw Lighthouse Grant.

\section{Compliance with ethical standards}

Conflict of interest The authors declare that they have no conflict of interest.

Open Access This article is distributed under the terms of the Creative Commons Attribution 4.0 International License (http://creativecommons.org/licenses/by/4.0/), which permits unrestricted use, distribution, and reproduction in any medium, provided you give appropriate credit to the original author(s) and the source, provide a link to the Creative Commons license, and indicate if changes were made.

\section{References}

Abramsson, M., \& Andersson, E. (2012). Residential mobility patterns of elderly-Leaving the house for an apartment. Housing Studies, 27(5), 582-604.

Abramsson, M., \& Andersson, E. K. (2016). Changing preferences with ageing-Housing choices and housing plans of older people. Housing, Theory and Society, 33, 217-241.

Angelini, V., \& Laferrere, A. (2012). Residential mobility of the European Elderly. CESifo Economic Studies, 58, 544-569.

Bayer, P., Fang, H., \& McMillan, R. (2014). Separate when equal? Racial inequality and residential segregation. Journal of Urban Economics, 82, 32-48.

Bayer, P., \& McMillan, R. (2012). Tiebout sorting and neighborhood stratification. Journal of Public Economics, 96, 1129-1143.

Bian, X. (2016). Leverage and elderly homeowners' decisions to downsize. Housing Studies, 31, $20-41$.

Bohle, Ph, Rawlings-Way, O., Finn, J., Ang, J., \& Kennedy, D. J. (2014). Housing choice in retirement: Community versus separation. Housing Studies, 29, 108-127.

Bonnet, C., Gobillon, L., \& Laferrere, A. (2010). The effect of widowhood on housing and location choices. Journal of Housing Economics, 19, 94-108.

Buchinsky, M., Gotlibovsky, C., \& Lifshitz, O. (2014). Residential location, work location, and labor market outcomes of immigrants in Israel. Econometrica, 82, 995-1054. 
Cambell, N. (2015). Designing for social needs to support aging in place within continuing care retirement communities. Journal of Housing and the Built Environment, 30, 645-665.

Chen, Y., \& Rosenthal, S. S. (2008). Local amenities and life-cycle migration: Do people move for jobs or fun? Journal of Urban Economics, 64, 519-537.

Colleman, T., Kearns, R. A., \& Wiles, J. (2016). Older adults' experiences of home maintenance issues and opportunities to maintain ageing in place. Housing Studies, 31, 964-983.

Costa-Font, J. (2013). Housing-related well-being in older people: The impact of environmental and financial influences. Urban Studies, 50(4), 657-673.

Costa-Font, J., Elivar, D., \& Mascarillo-Miró, O. (2009). Ageing in place? Exploring elderly people's housing preferences in Spain. Urban Studies, 46(2), 295-316.

De Jong, P., Rouwendal, J., Van Hattum, P., \& Brouwer, A. (2018). The older adult doesn't exist: using values to differentiate older adults in the Dutch housing market. Housing Studies, 33, 1014-1037.

Del Mistro, R., \& Hensher, D. A. (2009). Upgrading informal settlements in South Africa: Policy, rhetoric and what residents really value. Housing Studies, 24, 333-354.

Diamond, R. (2016). The determinants and welfare implications of US workers' diverging location choices by skill: 1980-2000. American Economic Review, 106, 479-524.

Dorfman, J. H., \& Mandich, A. M. (2016). Senior migration: Spatial considerations of amenity and health access drivers. Journal of Regional Science, 56, 96-133.

Eichholtz, P., \& Lindenthal, T. (2014). Demographics, human capital and the demand for housing. Journal of Housing Economics, 26, 19-32.

Engelhardt, G. V., \& Greenhalgh-Stanley, N. (2010). Home health care and the housing and living arrangements of the elderly. Journal of Urban Economics, 67, 226-238.

Eurostat. (2017). People in the EU-Population projections. Retrieved on June 26, 2019 from http://ec.europ a.eu/eurostat/statistics-explained/index.php/People_in_the_EU_-_population_projections.

Feng, J., Tang, S., \& Chuai, X. (2018). The impact of neighbourhood environments on quality of life of elderly people: Evidence from Nanjing, China. Urban Studies, 55, 2020-2039.

Gobillon, L., \& Wolff, F-Ch. (2011). Housing and location choices of retiring households: Evidence from France. Urban Studies, 48(2), 331-347.

Graves, P. E., \& Waldman, D. M. (1991). Multimarket amenity compensation and the behavior of the elderly. American Economic Review, 81, 1374-1381.

Hensher, D. A., Rose, J. M., \& Greene, W. H. (2015). Applied choice analysis: A primer. Cambridge: Cambridge University Press.

Herbers, D. J., \& Mulder, C. H. (2017). Housing and subjective well-being of older adults in Europe. Journal of Housing and the Built Environment, 32(3), 533-558.

Herbers, D. J., Mulder, C. H., \& Mòdenes, J. A. (2014). Moving out of homeownership in later life: The influence of the family and housing careers. Housing Studies, 29(7), 910-936.

Hillcoat-Nallétamby, S., \& Ogg, J. (2014). Moving beyond 'ageing in place': Older people's dislikes about their home and neighbourhood environments as a motive for wishing to move. Ageing \& Society, 34(10), 1771-1796.

Hofman, E., Halman, J. I. M., \& Ion, R. A. (2006). Variation in housing design: Identifying customer preferences. Housing Studies, 21(6), 929-943.

Hu, H., Geertman, S., \& Hooimeijer, P. (2014). Green apartments in Nanjing China: Do developers and planners understand the valuation by residents? Housing Studies, 29(1), 26-43.

Ibraimovic, T., \& Hess, S. (2017). A latent class model of residential choice behaviour and ethnic segregation preferences. Housing Studies, 33, 544-564.

Ibraimovic, T., \& Masiero, L. (2014). Do birds of a feather flock together? The impact of ethnic segregation preferences on neighbourhood choice. Urban Studies, 51(4), 693-711.

Kim, S. (2011). Intra-regional residential movement of the elderly: Testing a suburban-to urban migration hypothesis. Annals of Regional Science, 46, 1-17.

Kramer, C., \& Pfaffenbach, C. (2016). Should I stay or should I go? Housing preferences upon retirement in Germany. Journal of Housing and the Built Environment, 31, 239-256.

Liu, Y., Dijst, M., \& Geertman, S. (2017). The subjective well-being of older adults in Shanghai: The role of residential environment and individual resources. Urban Studies, 54, 1692-1714.

McFadden, D. (1978). Modelling the choice of residential location. Transportation Research Record, 673, $72-77$.

Morris, A. (2017). Housing tenure and the health of older Australians dependent on the age pension for their income. Housing Studies, 33, 77-95.

Mosca, I., Van der Wees, Ph, Mot, E., Wammes, J. J. G., \& Jeurissen, P. P. T. (2017). Sustainability of longterm care: Puzzling tasks ahead for policy-makers. International Journal of Health Policy Management, 6(4), 195-205. 
Nagib, W., \& Williams, A. (2016). Toward an autism-friendly home environment. Housing Studies, 32(2), $140-167$.

Noordelijke Rekenkamer. (2010). Eindrapport Blauwestad.

NVM Nederlandse vereniging van makelaars en taxateurs in onroerend goed. (2018). Transactiecijfers NVM-Regio Nederland, $1^{\mathrm{e}}$ kwartaal 2018.

Önder, A. S., \& Schlunk, H. (2015). State taxes, tax exemptions, and elderly migration. Journal of Regional Analysis and Policy, 45(1), 47-67.

Ong, R., Wood, G. A., Austen, S., Jefferson, Th, \& Haffner, M. E. A. (2015). Housing equity withdrawal in Australia: Prevalence, patterns and motivations in mid-to-late life. Housing Studies, 30, 1158-1181.

Painter, G., \& Lee, K. O. (2009). Housing tenure transitions of older households: Life cycle, demographic, and familial factors. Regional Science and Urban Economics, 39, 749-760.

Perkins, M. M., Ball, M. M., Whittington, F. J., \& Hollingsworth, C. (2012). Relational autonomy in assisted living: A focus on diverse care settings for older adults. Journal of Ageing Studies, 26, 214-225.

Pope, N. D., \& Kang, B. (2010). Residential relocation in later life: A comparison of proactive and reactive moves. Journal of Housing for the Elderly, 24(2), 193-207.

Rouwendal, J., \& Thomese, F. (2013). Homeownership and long-term care. Housing Studies, 28(5), $746-763$.

Schaffar, A., Dimou, M., \& El Mouhoub, M. (2018). The determinants of elderly migration in France. Papers in Regional Science, 98, 951-972.

Statistics Netherlands. (2018). Household income by tenure 2014. Retrieved on August 13, 2019 from https ://opendata.cbs.nl/statline/\#/CBS/nl/dataset/82958NED/table?dl=2459E.

Tatsiramos, K. (2006). Residential mobility and housing adjustment of older households in Europe. Discussion paper no. 2435, IZA, Bonn.

Teulings, C. N., Ossokina, I. V., \& de Groot, H. L. F. (2018). Land use, worker heterogeneity and welfare benefits of public goods. Journal of Urban Economics, 103, 67-82.

Tillema, T., van Wee, B., \& Ettema, D. (2010). The influence of (toll-related) travel costs in residential location decisions of households: A stated choice approach. Transportation Research Part A, 44, 785-796.

United Nations. (2015). World population ageing (p. 138). Retrieved on August 13, 2019 from http://www. un.org/en/development/desa/population/publications/pdf/ageing/WPA2015_Report.pdf.

Verhetsel, A., Kessels, R., Zijlstra, T., \& van Bavel, M. (2017). Housing preferences among students: Collective housing versus individual accommodations? A stated preference study in Antwerp (Belgium). Journal of Housing and the Built Environment, 32, 449-470.

Wright, C. J., Zeeman, H., \& Whitty, J. A. (2017). Design principles in housing for people with complex physical and cognitive disability: Towards an integrated framework for practice. Journal of Housing and the Built Environment, 32, 339-360.

Publisher's Note Springer Nature remains neutral with regard to jurisdictional claims in published maps and institutional affiliations. 